\title{
Role of anthocyanin and carotenoids in the adaptation of the photosynthetic apparatus of purple- and green-leaved cultivars of sweet basil (Ocimum basilicum) to high-intensity light
}

\author{
L.A. STETSENKO*, P.P. PASHKOVSKY ${ }^{*,+}$, R.A. VOLOSHIN* ${ }^{*}$, V.D. KRESLAVSKI**, \\ VL.V. KUZNETSOV*, and S.I. ALLAKHVERDIEV*,+
}

\author{
K.A. Timiryazev Institute of Plant Physiology, Russian Academy of Sciences, Botanicheskaya Street 35, \\ 127276 Moscow, Russia* \\ Institute of Basic Biological Problems, Russian Academy of Sciences, Institutskaya Street 2, 142290 Pushchino, \\ Moscow Region, Russia**
}

\begin{abstract}
Comparative studies of the adaptation of green- and purple-leaved Ocimum basilicum varieties, which differ in carotenoid and anthocyanin contents, to high-intensity light have been carried out. The plants were grown for $21 \mathrm{~d}$ under white lightemitting diode providing different light intensities [300, 550, and 1,350 $\mu$ mol(photon) $\left.\mathrm{m}^{-2} \mathrm{~s}^{-1}\right]$. During the experiment, fresh mass and relative water content, photosynthetic pigment and anthocyanin content, amount of total free phenolic compounds, and the contents of thiobarbituric acid reactive substances and $\mathrm{H}_{2} \mathrm{O}_{2}$ were analysed. The fluorescent parameters, which characterized the PSII activity in the leaves $\left(\mathrm{F}_{\mathrm{v}} / \mathrm{F}_{\mathrm{m}}, \mathrm{Y}_{(\mathrm{II})}\right)$, as well as the efficiency of dissipation of absorbed energy into heat $\left(\mathrm{Y}_{(\mathrm{NPQ})}, \mathrm{Y}_{(\mathrm{NO})}\right)$ and the fraction of the PSII open centres $\left(\mathrm{q}_{\mathrm{L}}\right)$, were determined. The obtained results are consistent with the concept of the important role of not only anthocyanin but also carotenoids in plant adaptation to high-intensity light.
\end{abstract}

Additional key words: chlorophyll a fluorescence; long-term growth; narrow-band diodes.

\section{Introduction}

High-intensity light (HIL) is a major stress factor that negatively affects the function of the photosynthetic apparatus (PA). During daylight, most plants are subjected to varying degrees of HIL exposure. Among the components of the PA, PSII and the $\mathrm{CO}_{2}$ fixation system are the most sensitive to light excess (Aro et al. 1993, Andersson and Aro 2001, Huang et al. 2018). Under conditions of light stress, when excessively absorbed light energy cannot be used in photochemical reactions, photoinhibition occurs, accompanied by a decrease in the intensity of photosynthesis, formation of reactive oxygen species (ROS), photooxidation of pigments, and destruction of the chloroplast structure (Allakhverdiev et al. 2008, Lefsrud et al. 2008, Trojak and Skowron 2017, Jensen et al. 2018). If the light intensity is too high, this leads to elevated contents of ROS, which, in addition to their damaging effects, can perform signalling functions. In response to increased ROS formation, various low-molecularmass antioxidants are synthesised and the activity of antioxidant enzymes is increased. Enzymatic antioxidants, carotenoids, phenolic compounds, including anthocyanin, play a significant role in ROS detoxification (Ouzounis et al. 2015, Mosadegh et al. 2018, Fan et al. 2019).

Carotenoids belong to the group of hydrophobic substances that are localized in chloroplasts as part of light-harvesting complexes (Rodriguez-Amaya 2019). Carotenoids, as accessory pigments, absorb light in the short-wavelength region of the spectrum, and then the absorbed energy is transferred to chlorophyll (Chl) (Frank and Cogdell 1996). Carotenoids are considered effective quenchers of singlet oxygen $\left({ }^{1} \mathrm{O}_{2}\right)$ and triplet Chls through a physical mechanism that involves the transfer of excitation energy leading to thermal deactivation. Additionally, leaf carotenoids can quench ${ }^{1} \mathrm{O}_{2}$ by a chemical mechanism involving their oxidation (Ramel et al. 2012). Carotenoids not only participate in the light reactions of photosynthesis and protect the PA from light excess but also support the structural stability of pigment-protein light-harvesting complexes (Yabuzaki 2017, Duarte et al. 2019). The constitutive carotenoid content in plants, as a majority

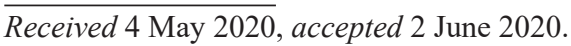

${ }^{+}$Corresponding author; e-mail: suleyman.allakhverdiev@,gmail.com, pashkovskiy.pavel@gmail.com

Abbreviations: $\mathrm{F}_{\mathrm{v}} / \mathrm{F}_{\mathrm{m}}$ - maximum quantum yield of PSII; HIL - high-intensity light; LED - light-emitting diode; PA - photosynthetic apparatus; $\mathrm{q}_{\mathrm{L}}$ - fraction of PSII open centres; ROS - reactive oxygen species; TBARs - thiobarbituric acid reactive substances; WT - wild type; $\mathrm{Y}_{(\mathrm{II})}$ - effective quantum yield of PSII; $\mathrm{Y}_{(\mathrm{NO})}$ - quantum yield of nonregulated nonphotochemical energy dissipation in PSII; $Y_{(\mathrm{NPQ})}$ - quantum yield of regulated nonphotochemical energy dissipation in PSII.

Acknowledgements: The study was carried out as part of state assignment No. 0106-2019-0001.
} 
of plant metabolites, is determined by the genome, but their quality and quantity are affected by external factors, primarily the light intensity and spectral composition. It was shown that, in Ginkgo biloba and Erigeron breviscapus plants, the carotenoid content decreases with shading and rises with increasing light intensity (Frank and Cogdell 1996).

Anthocyanins are water-soluble pigments and the final products of the late stage of the flavonoid biosynthetic pathway (Zhang et al. 2018). They are located in plant cells mainly in peripheral tissues, such as the upper mesophyll, which is most susceptible to HIL (Trojak and Skowron 2017). In plants, anthocyanins, similar to all flavonoids, are among the protective compounds that function as an optical filter, which prevents increased ROS production in the photosynthetic electron transport chain (Mierziak et al. 2014, Khan et al. 2018, De Keyser et al. 2019). The anthocyanin content varies significantly in different plant species, and their protection depends on various factors (Shoji et al. 2010, Ali and Abbasi 2014, Rodriguez-Amaya 2019). Anthocyanins protect PA from photons in excess that could be absorbed by the pigment of the antenna complex, while red leaves absorb plenty light because of nonphotosynthetic pigment (e.g. anthocyanin), thus, their photosynthetic tissues can receive fewer quanta than green leaves (Gould et al. 2000, Manetas 2006). Intensive accumulation of anthocyanin [up to $2.2-2.5 \mathrm{mg} \mathrm{g}^{-1}$ (FM)] was detected by periodically irradiating red-leaved basil with light $\left[120 \mu \mathrm{mol}\right.$ (photon) $\mathrm{m}^{-2} \mathrm{~s}^{-1}, 12 \mathrm{~h}$ each day] (Lobiuc et al. 2017). Additionally, the anthocyanin-rich Arabidopsis thaliana mutant pap1-D was less susceptible to PA damage than WT plants when exposed to HIL [800 $\mu$ mol(photon) $\mathrm{m}^{-2} \mathrm{~s}^{-1}, 2 \mathrm{~h}$ ] at $10^{\circ} \mathrm{C}$ (Gould et al. 2018). Anthocyanins are believed to be active in photoprotection when plants are subjected to prolonged exposure to the intense light of fluorescent lamps or natural sunlight at low temperatures when the capacities of other photoprotective mechanisms are exhausted (Berry and Björkman 1980, Gould et al. 2018, De Keyser et al. 2019). The anthocyanin content depends on the spectral characteristics of the light. A significant increase in the anthocyanin content was observed when growing Guzmania and Pelargonium under LEDs [40-100 $\mu \mathrm{mol}$ (photon) $\mathrm{m}^{-2} \mathrm{~s}^{-1}, 14 \mathrm{~d}$ ] in various combinations of blue and red light compared with plants grown under fluorescent lamps (Owen and Lopez 2017, De Keyser et al. 2019).

An important role in plant photoprotection is played by numerous phenolic compounds that can inactivate free radicals and protect cells from ROS action (Carvalho et al. 2016, Kalisz et al. 2016, Masondo et al. 2019). When studying plants under UV radiation, shading, and water deficiency, an increase in the total phenolic content, including the total flavonoid content, inhibition of growth processes, and increased resistance to various stress factors (Javanmardi et al. 2003, Bidel et al. 2007, Cheynier et al. 2013, Mosadegh et al. 2018) were observed. The main sites of their biosynthesis are plastids, mitochondria, and the endoplasmic reticulum, and the localization sites are vacuoles, cell wall, nucleus, and chloroplasts (Cheynier et al. 2013).
In the work of Tattini et al. (2014), the effect of highintensity sunlight in the range of $600-2,000 \mu \mathrm{mol}$ (photon) $\mathrm{m}^{-2} \mathrm{~s}^{-1}$ on the green- and purple-leaved $O$. basilicum varieties was studied. These authors concluded that at high light the purple-leaved is more tolerant than green-leaved variety, as metabolic cost of photoprotective mechanisms is low and the increase in biomass production is high passing from shade to full sun, and also that epidermal coumaroyl anthocyanins have a tremendous impact on the response mechanisms to high light stress, but they are unusual in being effective in absorbing mostly UV-B than green-yellow solar wavelengths. On the other hand, sunlight is not optimal for the growth of most plants and contains a lot of infrared radiation, which causes heating and complicates studying the mechanism of adaptation to HIL separately from temperature. Hosseini et al. (2019) showed that in both purple and green basil varieties, combination of red and blue LEDs (70 red:30 blue) caused favorable growth, pigmentation, and Chl fluorescence parameters of basil plants $\left[250 \pm 10 \mu \mathrm{mol}\right.$ (photon) $\left.\mathrm{m}^{-2} \mathrm{~s}^{-1}\right]$. Based on this we tried to implement a one-way experiment model to determine how different varieties of basil adapt to the prolonged exposure to the most suitable light for them separately from the temperature influence. For this, we used narrow-band diodes without IR and UV wavelengths, along with a collecting lens and cooling phytotron boxes.

The existence of $O$. basilicum varieties with different accumulations of anthocyanin and carotenoids makes them a convenient model system to assess the ability of the PA to adapt to HIL, as well as to establish the role of anthocyanin and carotenoids in these processes. In this regard, studies of the species-specific mechanisms of plant adaptation using various strategies to avoid oxidative stress caused by HIL are of interest. Thus, we aimed to investigate the PA adaptation of purple- and green-leaved O. basilicum to long-term growth at HIL [300-1,350 $\mu$ mol(photon) $\left.\mathrm{m}^{-2} \mathrm{~s}^{-1}\right]$.

\section{Materials and methods}

Plant growth and experimental design: We investigated Ocimum basilicum L., an annual medicinal and spicy aromatic plant of the Lambaceae (Lamiaceae) family. Two varieties of basil, lemon basil ( $O$. basilicum $\times$ $O$. americanum) and 'Rubin' basil (O. basilicum 'Rubin'), contrasting in leaf colour, were used in the study. Basil seeds were sown in perlite and, at the stage of the second pair of true leaves, the seedlings were transferred to a Hoagland media (Hoagland and Arnon 1950) and were grown in a climatic chamber in conditions of 12/12-h light/dark regime, $150 \pm 10 \mu \mathrm{mol}$ (photon) $\mathrm{m}^{-2} \mathrm{~s}^{-1}$ (Philips L36W/765 fluorescent lamps, Poland), $22 \pm 3^{\circ} \mathrm{C}$, relative air humidity of $65 \pm 5 \%$. After four weeks, the control plants were fixed and primary analyses were performed. The remaining plants were placed in a phytotron chamber at $22 \pm 3^{\circ} \mathrm{C}$ and a relative air humidity of $65 \pm 5 \%$, equipped with white LEDs (100 W, EPISTAR, Taiwan), emission spectra in two maxima [blue spectral regions $(450 \mathrm{~nm})$ :red spectral regions $(660 \mathrm{~nm})=1: 3$ ] [the spectral characteristics of the light sources were determined using the USB2000 
spectrometer (OceanOptics, USA); Fig. 1S, supplement], a colour temperature of $3,300 \mathrm{~K}$, and a collecting lens $(\mathrm{d}=50 \mathrm{~mm})$, providing light intensities of 300,550 , and $1,350 \mu \mathrm{mol}\left(\right.$ photon) $\mathrm{m}^{-2} \mathrm{~s}^{-1}$ ( $\mathrm{Li}-250 \mathrm{~A}, \mathrm{Li}-\mathrm{COR}$, USA) and eliminating the heat influence. In experimental plants, every $7 \mathrm{~d}$ for three weeks, physiological, biochemical, and photosynthetic parameters were measured. Some plants were fixed in liquid nitrogen and stored at $-70^{\circ} \mathrm{C}$ until other analyses were performed.

Determination of the photochemical activity: The fluorescent parameters were measured using an IMAGINGPAM fluorometer ( Walz, Germany) on plants adapted to the dark (30 min). After a pulse of saturating light, the leaves were kept for $1 \mathrm{~min}$ in the dark, and then they were exposed to actinic light for $5 \mathrm{~min}$, followed by saturating light pulses during which the parameters were measured. The areas of interest were selected on the leaf so that measurements from each pixel of this zone provided averaged values over the entire leaf surface. During one measurement, three leaves of the second tier were used. The leaves were placed in front of the camera at a distance of $7 \mathrm{~cm}$, and then six measured zones were allocated on each leaf. The shape of the zones was circular (radius: $0.86 \mathrm{~mm}$, area: $2.35 \mathrm{~mm}^{2}$ ). The measuring light, actinic light, and saturating pulses were provided by blue LEDs $(450 \mathrm{~nm})$. The intensity of the actinic blue light was $220 \mu \mathrm{mol}$ (photon) $\mathrm{m}^{-2} \mathrm{~s}^{-1}$. The intensity of the measuring light was $0.5 \mu \mathrm{mol}$ (photon) $\mathrm{m}^{-2} \mathrm{~s}^{-1}$. The intensity and duration of the saturation pulse were 5,000 $\mu \mathrm{mol}$ (photon) $\mathrm{m}^{-2} \mathrm{~s}^{-1}$ and $800 \mathrm{~ms}$, respectively. The primary data processing and parameter calculations were performed using Imaging Win v. 2.41a software ( Walz, Germany) and the following formulas (Kramer et al. 2004, Klughammer and Schreiber 2008, Goltsev et al. 2016): (1) $\mathrm{F}_{\mathrm{v}} / \mathrm{F}_{\mathrm{m}}$, maximal PSII quantum yield. It is measured similarly to the $\mathrm{Y}_{(\mathrm{II})}$ but only for dark-adapted leaves. $\mathrm{F}_{\mathrm{v}} / \mathrm{F}_{\mathrm{m}}=\left(\mathrm{F}_{\mathrm{m}}-\mathrm{F}_{0}\right) / \mathrm{F}_{\mathrm{m}}$, where $\mathrm{F}_{\mathrm{m}}$ is the maximal fluorescence yield of the dark-adapted sample when all the PSII centres are closed and $\mathrm{F}_{0}$ is the minimal fluorescence yield of dark-adapted samples when all the PSII centres are open. (2) $\mathrm{Y}_{(\mathrm{II})}$, effective PSII quantum yield. This parameter constitutes the fraction of energy that is photochemically converted in the PSII, $\mathrm{Y}_{(\mathrm{II})}=\left(\mathrm{F}_{\mathrm{m}}{ }^{\prime}-\mathrm{F}_{\mathrm{s}}\right) / \mathrm{F}_{\mathrm{m}}{ }^{\prime}$, where $\mathrm{F}_{\mathrm{m}}{ }^{\prime}$ is the maximal fluorescence yield of light-adapted samples and $F_{s}$ is the relative steady-state fluorescence yield. (3) $q_{L}$, a parameter estimating the fraction of PSII open centres. It is based on a lake model for photosynthetic unity (Kramer et al. 2004); $\mathrm{q}_{\mathrm{L}}=\left[\left(\mathrm{F}_{\mathrm{m}}{ }^{\prime}-\mathrm{F}_{\mathrm{s}}\right) /\left(\mathrm{F}_{\mathrm{m}}{ }^{\prime}-\mathrm{F}_{0}^{\prime}\right)\right] \times\left(\mathrm{F}_{0}{ }^{\prime} / \mathrm{F}_{\mathrm{s}}\right)$, where $\mathrm{F}_{0}{ }^{\prime}$ is minimal fluorescence yield of light-adapted samples. (4) NPQ, nonphotochemical fluorescence quenching, $\mathrm{NPQ}=\mathrm{F}_{\mathrm{m}} / \mathrm{F}_{\mathrm{m}}{ }^{\prime}-1$. (5) $\mathrm{Y}_{(\mathrm{NO})}$, the quantum yield of nonregulated energy dissipation in PSII. The yield reflects the fraction of the energy that is passively dissipated in the form of heat and fluorescence, $\mathrm{Y}_{(\mathrm{NO})}=1 /\left[\mathrm{NPQ}+1+\mathrm{q}_{\mathrm{L}} \times\right.$ $\left.\left(\mathrm{F}_{\mathrm{m}} / \mathrm{F}_{0}-1\right)\right]$. (6) $\mathrm{Y}_{(\mathrm{NPQ})}$, the quantum yield of regulated energy dissipation in PSII. The fraction of energy dissipated in the form of heat via the regulated photoprotective mechanism, $\mathrm{Y}_{(\mathrm{NPQ})}=1-\mathrm{Y}_{(\mathrm{II})}-\mathrm{Y}_{(\mathrm{NO})}$.

Pigment and water content: The biomass of the aboveground part was determined using the gravimetric method to an accuracy of $0.01 \mathrm{mg}$ (OHAUS Scout STX, USA). The samples were then dried for three days $\left(60^{\circ} \mathrm{C}\right)$ to a constant mass and then weighed again.

The photosynthetic pigment (Chls $a$ and $b$, Car) was determined using the Lichtenthaler (1987) method. The pigments were extracted with $80 \%$ acetone in $3-4$ multiple repetitions until the samples were completely bleached at $4^{\circ} \mathrm{C}$. The optical density of the extracts was determined at wavelengths of 470, 648, and $663 \mathrm{~nm}$ using a spectrophotometer (Genesys $10 \mathrm{UV}$, Thermo Fisher Scientific, USA).

Anthocyanin and total free phenol content: The anthocyanin content was determined using the Giusti and Wrolstad (2001) method. Cyanidin solutions (Gee Lawson Chemicals, UK) were used to make the calibration curve

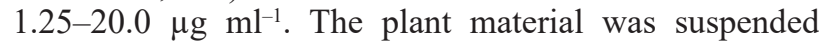
in acid/alcohol mixture (97 $\mathrm{ml}$ of $96 \%$ ethanol $+3 \mathrm{ml}$ of concentrated $\mathrm{HCl}$ ). The content of anthocyanin was determined at $550 \mathrm{~nm}$ (Genesys $10 \mathrm{UV}$, Thermo Fisher Scientific, USA).

The total phenol compounds from plant material were extracted with $96 \%$ ethanol. Content was determined using the Folin-Ciocalteu reagent according to the Singleton et al. (1999) method at $725 \mathrm{~nm}$ (Genesys $10 \mathrm{UV}$, Thermo Fisher Scientific, USA). Gallic acid (Sigma, Germany) was used as a standard solution for calibration at a concentration of $50-450 \mu \mathrm{g} \mathrm{ml} \mathrm{m}^{-1}$.

$\mathbf{H}_{2} \mathrm{O}_{2}$ content: The content of hydrogen peroxide was determined spectrophotometrically using the FOX method (ferrous oxidation-xylenol orange method) (Bellincampi et al. 2000), which is based on the oxidation of $\mathrm{Fe}^{2+}$ by hydrogen peroxide to $\mathrm{Fe}^{3+}$ (catalysed by sorbitol) with the formation of coloured compounds. To this end, 70-80 mg of plant tissue was extracted with chilled acetone and centrifuged for $10 \mathrm{~min}$ at $12,000 \times \mathrm{g}$. An equal volume of FOX reagent (Gee Lawson Chemicals, UK) was added to the obtained extract and kept for $45 \mathrm{~min}$ at room temperature. A mixture of FOX reagent and acetone at a ratio of 1:1 was used as a control. The optical density was measured at a wavelength of $560 \mathrm{~nm}$ using a spectrophotometer (Genesys $10 \mathrm{UV}$, Thermo Fisher Scientific, USA).

TBARs content: TBARs were determined using the Heath and Packer (1968) method, based on the formation of a coloured complex of TBARs with thiobarbituric acid (Sigma, Germany) through heating. The concentration of TBARs was determined spectrophotometrically by measuring the optical density on a Genesys $10 \mathrm{UV}$ spectrophotometer (Thermo Fisher Scientific, USA) at 532 and $600 \mathrm{~nm}$ wavelengths. As a TBARs standard 1,1,3,3-tetramethoxypropane (Sigma, Germany) in deionized water was used.

Statistical analysis: At least three independent biological experiments were carried out. The analysis of each point of each variant included six plants. Three leaves of the second and third tiers of plants formed in the new lighting conditions were used in the analyses. Data were represented 
as mean $\pm \mathrm{SD}$. One-way analysis of variance $(A N O V A)$ followed by Duncan's method were performed using SigmaPlot 12.3 (Systat Software Inc., USA). Different letters were used to represent significance at $p<0.05$.

\section{Results}

Biomass and water content: The aerial mass of both basil varieties increased with increasing light intensity (Table 1, Fig. 1). However, under all studied light conditions, the biomass accumulation was higher in green-leaved than that in purple-leaved plants. At $21 \mathrm{~d}$, the mass of the aboveground part of green-leaved plants grown at a light intensity of 1,350 $\mu \mathrm{mol}\left(\right.$ photon) $\mathrm{m}^{-2} \mathrm{~s}^{-1}$ increased 2.6 times, and the mass of purple-leaved plants increased, on average, 1.5 times compared with plants that were grown at $300 \mu \mathrm{mol}$ (photon) $\mathrm{m}^{-2} \mathrm{~s}^{-1}$ (Table 1). A greater increase in green-leaved plants was also observed at other higher light intensities. The water content of the leaves of both basil varieties mostly decreased with increasing light intensity (Table 1).

Importantly, green-leaved plants were less susceptible to leaf dehydration than purple-leaved plants. At $21 \mathrm{~d}$ of growth at $1,350 \mu \mathrm{mol}$ (photon) $\mathrm{m}^{-2} \mathrm{~s}^{-1}$, the water content decreased by an average of $4 \%$ in the green-leaved plants and by an average of $22 \%$ in purple-leaved plants compared with the initial-point control values (Table 1).

\section{Photochemical activity}

Maximum quantum yield of PSII: The $F_{v} / F_{m}$ in the green-leaved plants throughout the experiment remained high, within $0.77-0.80$, and only decreased to 0.70 at $21 \mathrm{~d}$ at $1,350 \mu \mathrm{mol}$ (photon) $\mathrm{m}^{-2} \mathrm{~s}^{-1}$ (Fig. 2). In purple-leaved plants, the basilic $F_{v} / F_{m}$ values at $7 \mathrm{~d}$ at 550 and 1,350 $\mu$ mol(photon) $\mathrm{m}^{-2} \mathrm{~s}^{-1}$ were slightly lower than that at $150 \mu \mathrm{mol}$ (photon) $\mathrm{m}^{-2} \mathrm{~s}^{-1}$ (approximately 0.74 ), however, at 14 and $21 \mathrm{~d}$ at $550 \mu \mathrm{mol}$ (photon) $\mathrm{m}^{-2} \mathrm{~s}^{-1}$, the $\mathrm{F}_{\mathrm{v}} / \mathrm{F}_{\mathrm{m}}$ was close to the initial values (Fig. 2A).

Effective quantum yield of PSII: In green-leaved plants, at all the used light intensities, the $\mathrm{Y}_{\text {(II) }}$ fluctuated within $0.5 \pm 0.05$, indicating the high efficiency of the PA. At 550 and $1,350 \mu \mathrm{mol}$ (photon) $\mathrm{m}^{-2} \mathrm{~s}^{-1}$, the plants quickly adapted to light conditions, maintaining a sufficiently high effective quantum yield. In purple-leaved plants, at $7 \mathrm{~d}$, all the variants showed the same $\mathrm{Y}_{(\mathrm{II})}$ levels as the control, however, under HIL, the $\mathrm{Y}_{\text {(II) }}$ significantly increased. The purple-leaved plants grown at $550 \mu$ mol(photon) $\mathrm{m}^{-2} \mathrm{~s}^{-1}$ for 14 and $21 \mathrm{~d}$ were the most effective. The $\mathrm{Y}_{\text {(II) }}$ value was lower than that of the control at $21 \mathrm{~d}$ under 1,350 $\mu \mathrm{mol}$ (photon) $\mathrm{m}^{-2} \mathrm{~s}^{-1}$ (Fig. $2 B$ ). The distribution of the $\mathrm{Y}_{\text {(II) }}$ value over the leaf in plants grown at two light intensities [550 and 1,350 $\mu \mathrm{mol}$ (photon) $\mathrm{m}^{-2} \mathrm{~s}^{-1}$ ] is shown in Fig. 3 . In all cases, a high and uniform distribution of $Y_{(\text {II) }}$ over the leaf was observed, excluding purple-leaved plants grown at $1,350 \mu \mathrm{mol}$ (photon) $\mathrm{m}^{-2} \mathrm{~s}^{-1}$. Along with areas where the PA works efficiently (Fig. 3, in green), several areas had a low effective quantum yield (in red). A comparison of $\mathrm{q}_{\mathrm{L}}$ revealed the same patterns: a high $\mathrm{q}_{\mathrm{L}}$ value in green-leaved plants and a very low $\mathrm{q}_{\mathrm{L}}$ value in purple-leaved plants under $1,350 \mu$ mol(photon) $\mathrm{m}^{-2} \mathrm{~s}^{-1}$ but an intermediate $\mathrm{q}_{\mathrm{L}}$ value at $550 \mu \mathrm{mol}$ (photon) $\mathrm{m}^{-2} \mathrm{~s}^{-1}$ in purple-leaved plants. At the same time, a pronounced uneven distribution of this value over the leaves was found (Fig. 3). This parameter is an indicator of a $Q_{A}$ redox state (Kramer et al. 2004). Hence, the redox state of $\mathrm{Q}_{\mathrm{A}}$ has heterogeneous distribution within the leaf.

\section{Nonphotochemical chlorophyll fluorescence quenching:} The NPQ in green-leaved plants was low (0.2-0.3) and on $21^{\text {th }}$ day it decreased from 0.3 at $550 \mu \mathrm{mol}$ (photon) $\mathrm{m}^{-2} \mathrm{~s}^{-1}$ to 0.2 at $1,350 \mu \mathrm{mol}$ (photon) $\mathrm{m}^{-2} \mathrm{~s}^{-1}$, whereas in purpleleaved plants it increased from 0.2 at $550 \mu \mathrm{mol}$ (photon) $\mathrm{m}^{-2} \mathrm{~s}^{-1}$ and 0.6 at 1,350 $\mu \mathrm{mol}$ (photon) $\mathrm{m}^{-2} \mathrm{~s}^{-1}$.

The $\mathrm{Y}_{(\mathrm{NPQ})}$ level in green-leaved plants increased in the variant grown at $550 \mu \mathrm{mol}$ (photon) $\mathrm{m}^{-2} \mathrm{~s}^{-1}$ at 14 and $21 \mathrm{~d}$ compared with that at $7 \mathrm{~d}$ (Fig. 2C). However, in the variant grown at $1,350 \mu \mathrm{mol}($ photon $) \mathrm{m}^{-2} \mathrm{~s}^{-1}, \mathrm{Y}_{(\mathrm{NPQ})}$ was at the control level. The green-leaved $\mathrm{Y}_{(\mathrm{NO})}$ value increased at 550 and $1,350 \mu \mathrm{mol}$ (photon) $\mathrm{m}^{-2} \mathrm{~s}^{-1}$ except for that of the variant grown at $550 \mu$ mol(photon) $\mathrm{m}^{-2} \mathrm{~s}^{-1}$ at $21 \mathrm{~d}$ (Fig. $2 D$ ). In purple-leaved plants, the $\mathrm{Y}_{(\mathrm{NPQ})}$ value in the control was higher than that in green-leaved plants. On the $14^{\text {th }}$ day of the experiment, this parameter decreased both at 550 and $1,350 \mu \mathrm{mol}$ (photon) $\mathrm{m}^{-2} \mathrm{~s}^{-1}$ with a subsequent increase. The highest $\mathrm{Y}_{(\mathrm{NPQ})}$ values for purple-leaved plants were observed at $1,350 \mu \mathrm{mol}$ (photon) $\mathrm{m}^{-2} \mathrm{~s}^{-1}$ on day 21 (Fig. 2C). The $\mathrm{Y}_{(\mathrm{NO})}$ value at $7 \mathrm{~d}$ under 550 and 1,350 $\mu$ mol(photon) $\mathrm{m}^{-2} \mathrm{~s}^{-1}$ was at the control level. A gradual decrease in $\mathrm{Y}_{(\mathrm{NO})}$ was then observed, and, by the end of the experiment, in the $1,350 \mu \mathrm{mol}$ (photon) $\mathrm{m}^{-2} \mathrm{~s}^{-1}$ variant reached the lowest values (Fig. 2D). Comparison of the $\mathrm{Y}_{\text {(NO) }}$ values in the two types of plants on the $21^{\text {st }}$ day of cultivation at two light intensities revealed a uniform distribution of this parameter over the leaf surface, but $\mathrm{Y}_{(\mathrm{NO})}$ was higher in a dose-dependent manner (Fig. 3). Conversely, in purple-leaved plants, $\mathrm{Y}_{(\mathrm{NO})}$ decreased and $\mathrm{Y}_{(\mathrm{NPQ})}$ increased at higher light intensities. Heterogeneous distribution of $\mathrm{Y}_{(\mathrm{NPQ})}$ over the leaf surface was observed (Fig. 3).

Pigment content: Comparison of the Chl $a$ and $b$ accumulation dynamics under prolonged intense light revealed varietal differences (Table 1). In green-leaved basil plants, the content of Chl $a$ and $b$ in all experimental variants did not decrease below the initial level and the highest values of the Chl content were observed at light intensities of 300 and $550 \mu \mathrm{mol}$ (photon) $\mathrm{m}^{-2} \mathrm{~s}^{-1}$ (Table 1). In the purpleleaved basil plants, the Chl $a$ and $b$ content at 300 and $550 \mu \mathrm{mol}$ (photon) $\mathrm{m}^{-2} \mathrm{~s}^{-1}$ increased for $14 \mathrm{~d}$, however, at $21 \mathrm{~d}$ at $550 \mu \mathrm{mol}$ (photon) $\mathrm{m}^{-2} \mathrm{~s}^{-1}$, a decrease in the Chl contents was observed compared with that of the initialpoint control. A significant decrease in the contents of Chl $a$ and $b$ were observed under 1,350 $\mu$ mol(photon) $\mathrm{m}^{-2} \mathrm{~s}^{-1}$ throughout the entire experimental period, likely indicating the presence of a photoinhibition process in plants (Table 1).

The carotenoid content in the leaves of the control plants of both basil varieties did not significantly differ 


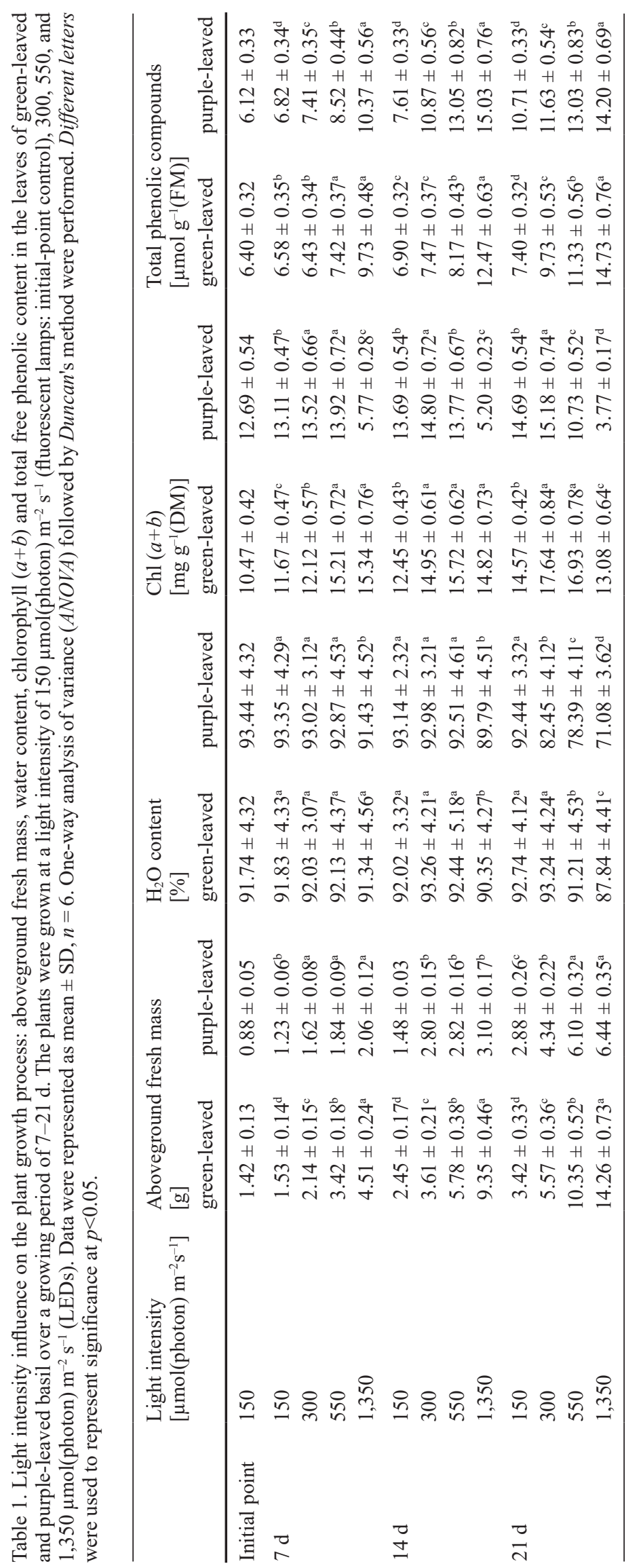


and averaged $0.73 \mathrm{mg} \mathrm{g}^{-1}(\mathrm{DM})$ (Fig. 4A,B). Exposure of the plants at varying light intensities revealed varietal differences in the dynamics of changes in the carotenoid content. In green-leaved plants, the carotenoid content was enhanced with increasing time exposure, at $21 \mathrm{~d}$, at

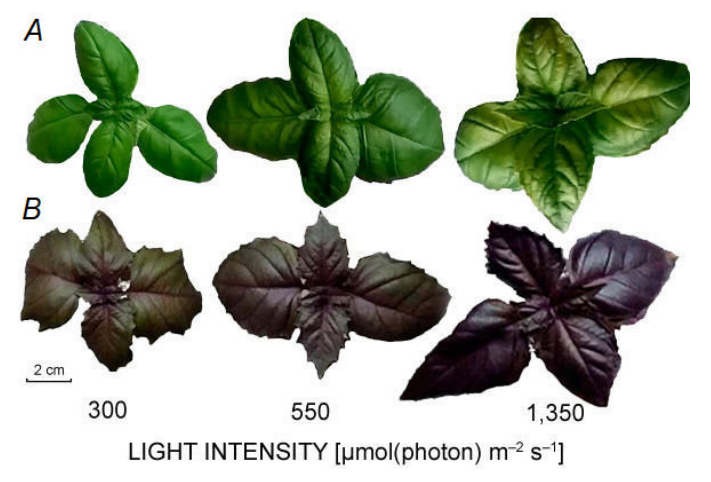

Fig. 1. Leaf images of green-leaved $(A)$ and purple-leaved basil (B) plants grown on hydroponics for $14 \mathrm{~d}$ at different light intensities: 300,550 and $1,350 \mu$ mol(photon) $\mathrm{m}^{-2} \mathrm{~s}^{-1}$.
300,550 , and $1,350 \mu \mathrm{mol}$ (photon) $\mathrm{m}^{-2} \mathrm{~s}^{-1}$, the carotenoid content exceeded that of the initial control values by an average of 1.8, 1.6, and 1.4 times, respectively (Fig. $4 A$ ) The dynamics of carotenoid accumulation in green-leaved basil at light intensities of 300 and $550 \mu \mathrm{mol}$ (photon) $\mathrm{m}^{-2} \mathrm{~s}^{-1}$ increased, a slight decrease was observed only at $1,350 \mu \mathrm{mol}$ (photon) $\mathrm{m}^{-2} \mathrm{~s}^{-1}$ (Fig. $4 A$ ). In purple-leaved basil plants, with an increase in the light intensity and duration of light exposure, inhibition of carotenoid synthesis occurred compared with the initial-point control value (Fig. 4B). The decrease in the carotenoid content in purple-leaved basil on the $21^{\text {st }}$ day of the experiment at light intensities of 300,550 , and $1,350 \mu \mathrm{mol}$ (photon) $\mathrm{m}^{-2} \mathrm{~s}^{-1}$ averaged 7,17 , and $66 \%$, respectively, compared with that of the initial-point control (Fig. 4B).

Anthocyanin content: The constitutive anthocyanin content in green-leaved basil leaves averaged $0.7 \mu \mathrm{g} \mathrm{g}^{-1}(\mathrm{FM})$ (Fig. 4C,D). Because of green-leaved basil exposure to 300 and $1,350 \mu \mathrm{mol}$ (photon) $\mathrm{m}^{-2} \mathrm{~s}^{-1}$ for $21 \mathrm{~d}$, the anthocyanin contents in the leaves increased by an average of 20 and $35 \%$, respectively (Fig. $4 C$ ). The leaves of purple basil

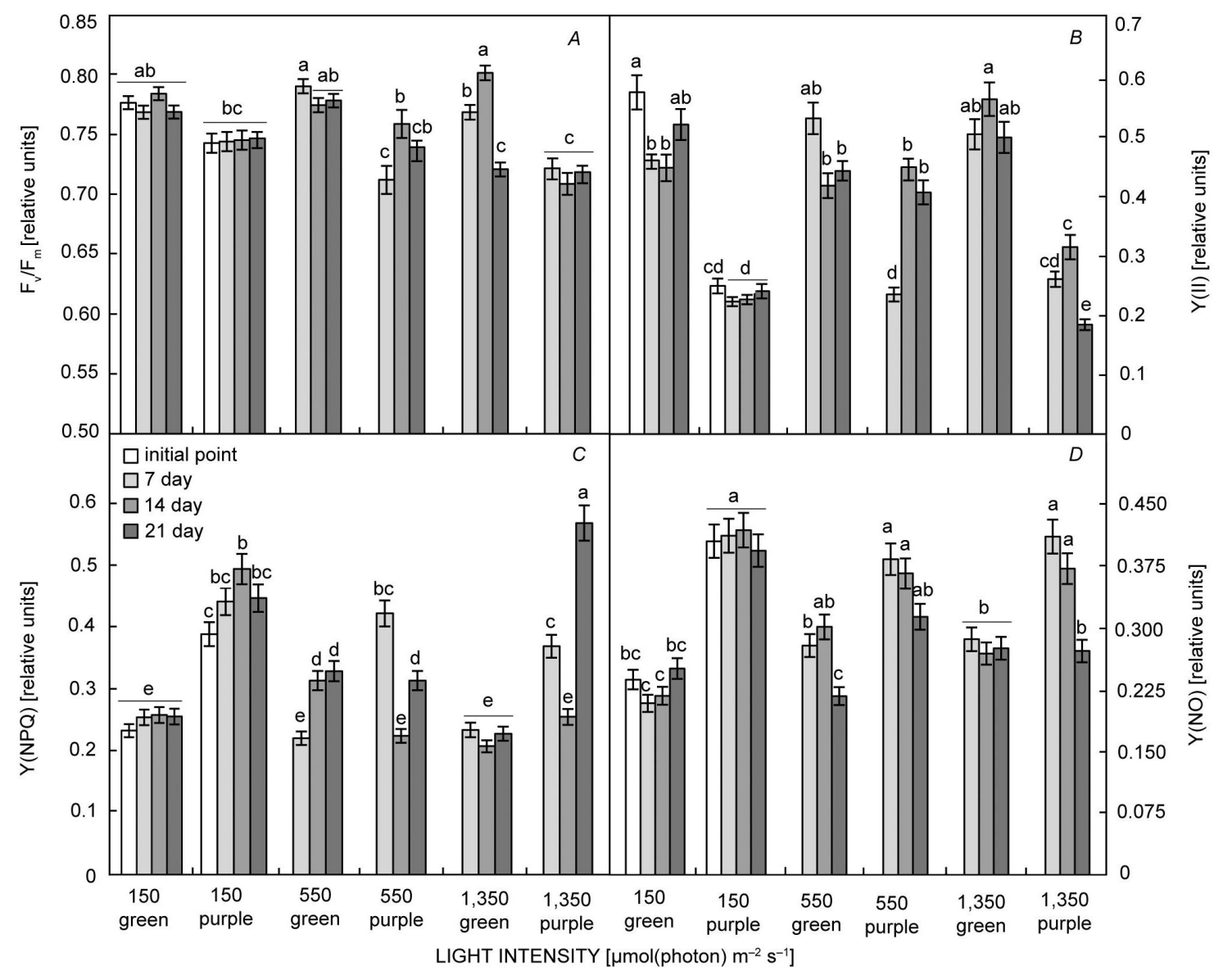

Fig. 2. Effect of light intensity and exposure time $(7,14,21 \mathrm{~d})$ on the PSII maximum quantum yield $\left(\mathrm{F}_{\mathrm{v}} / \mathrm{F}_{\mathrm{m}}\right)(A)$, effective quantum yield $\left(\mathrm{Y}_{(\mathrm{II})}\right)(B)$, quantum yields of regulated $\left(\mathrm{Y}_{(\mathrm{NPO})}\right)(C)$, and nonregulated $\left(\mathrm{Y}_{(\mathrm{NO})}\right)(D)$ energy dissipation in green-leaved and purpleleaved basilic leaves. The plants were grown for $21 \mathrm{~d}$ at different light intensities: $150 \mu$ mol(photon) $\mathrm{m}^{-2} \mathrm{~s}^{-1}$ (initial point), 550, and $1,350 \mu \mathrm{mol}$ (photon) $\mathrm{m}^{-2} \mathrm{~s}^{-1}$. Data were represented as mean $\pm \mathrm{SD}, n=6$. One-way analysis of variance (ANOVA) followed by Duncan's method were performed. Different letters were used to represent significance at $p<0.05$. 

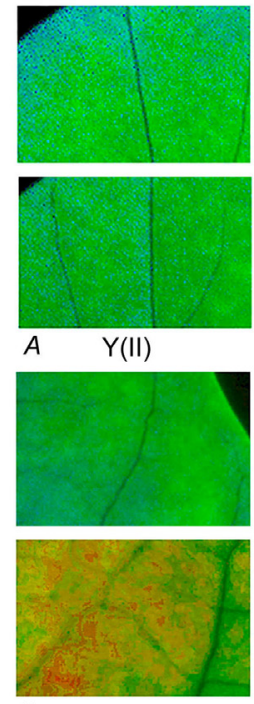

B $\quad \mathrm{Y}(\mathrm{II})$

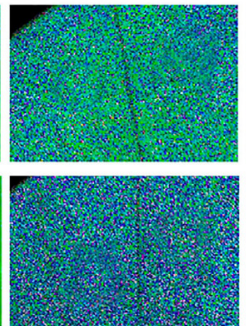

$\mathrm{q}_{\mathrm{L}}$

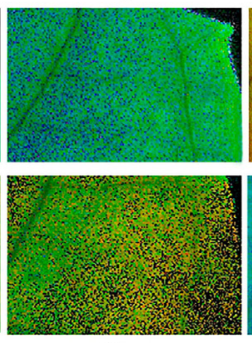

$\mathrm{q}_{\mathrm{L}}$

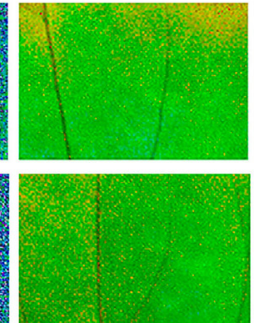

$Y(N P Q)$

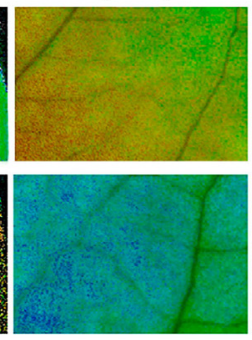

Y(NPQ)

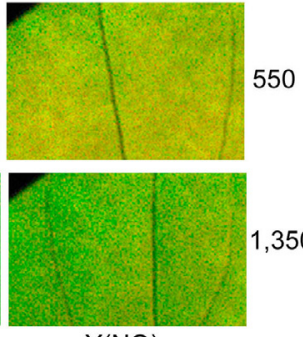

$\mathrm{Y}(\mathrm{NO})$

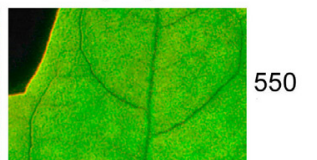

$\mathrm{Y}(\mathrm{NO})$
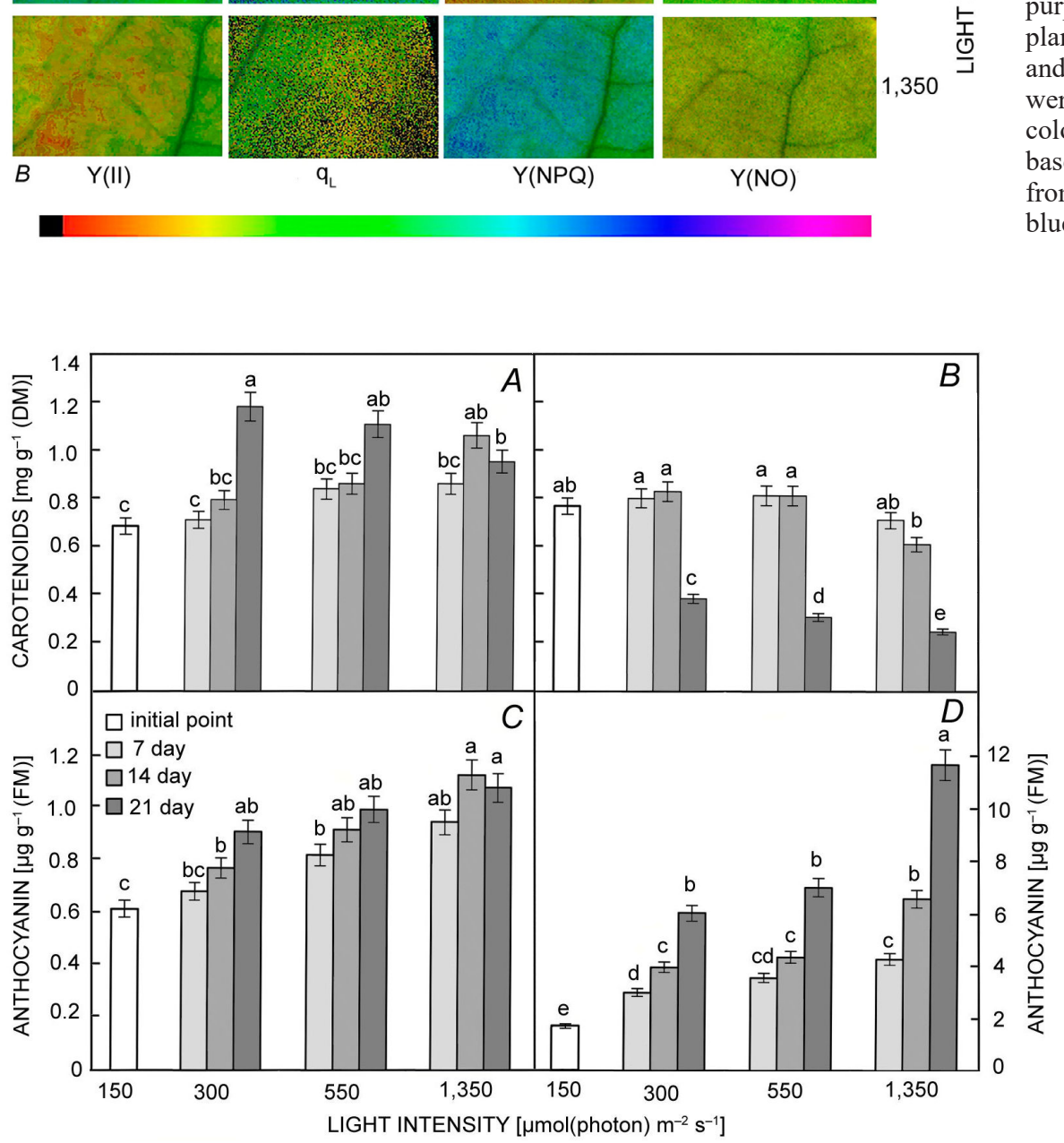

Fig. 4. Effect of light of different intensities and exposure time $(7,14$, and $21 \mathrm{~d}$ ) on the content of carotenoids $(A, B)$ and anthocyanin $(C, D)$ in the leaves of green-leaved $(A, C)$ and purple-leaved basil $(C, D)$ plants grown at various light intensities: 150 (initial point), 300, 550, and $1,350 \mu \mathrm{mol}$ (photon) $\mathrm{m}^{-2} \mathrm{~s}^{-1}$. Data were represented as mean $\pm \mathrm{SD}, n=6$. Oneway analysis of variance $(A N O V A)$ followed by Duncan's method were performed. Different letters were used to represent significance at $p<0.05$. with an intense violet colour were characterized by a high content of anthocyanin that averaged $1.8 \mu \mathrm{g} \mathrm{g}^{-1}$ (FM) in the control plants (Fig. 4D). The increase in light intensity during the cultivation of purple-leaved basil experimental plants was accompanied by a significant increase in the anthocyanin content in all variants compared with that of green-leaved basil (Fig. 4D). At a light intensity of $1,350 \mu \mathrm{mol}$ (photon) $\mathrm{m}^{-2} \mathrm{~s}^{-1}$, the anthocyanin content in purple-leaved basil leaves at 14 and $21 \mathrm{~d}$ increased 3.5 and 6 times, respectively, compared with that of the initialpoint control (Fig. 4D).
Total free phenolic content: Regarding the total free phenol content, the green-leaved and purple-leaved basil at the beginning of the experiment did not differ significantly and the free phenolic content was in the range of 5-7 $\mu \mathrm{mol} \mathrm{g} \mathrm{g}^{-1}$ (FM) (Table 1). HIL irradiation caused an increase in the free phenol content in the leaves. At $14 \mathrm{~d}$ of exposure at $1,350 \mu \mathrm{mol}$ (photon) $\mathrm{m}^{-2} \mathrm{~s}^{-1}$, the phenolic content increased on average two times in green-leaved basil and 2.5 times in purple-leaved basil compared with the initial-point control values $\left[150 \mu \mathrm{mol}\left(\right.\right.$ photon) $\mathrm{m}^{-2} \mathrm{~s}^{-1}$ ] (Table 1). At $21 \mathrm{~d}$, a further increase in the total free phenol 
content was observed in the leaves of green basil grown at 300,550 , and $1,350 \mu \mathrm{mol}$ (photon) $\mathrm{m}^{-2} \mathrm{~s}^{-1}$ compared with the initial-point control by averages of $1.5,2.8$, and 3.3 times, respectively (Table 1). An increase in exposure time from 14 to $21 \mathrm{~d}$ did not significantly affect the content of the phenolic compounds in purple-leaved basil leaves.

TBARs content: The TBARs content in the leaves of both varieties increased most significantly during the first week of exposure and was dose-dependent (Fig. 5A,B). At a light intensity of $1,350 \mu \mathrm{mol}$ (photon) $\mathrm{m}^{-2} \mathrm{~s}^{-1}$ in the green-leaved basil, the TBARs content increased on average 2 times over $7 \mathrm{~d}$ (Fig. $5 A$ ), and an average of 3 times in the purpleleaved basil leaves, compared with control plants (Fig. $5 B$ ). On the $21^{\text {st }}$ day of the experiment, in both varieties, at light intensities of 300,550 , and $1,350 \mu \mathrm{mol}$ (photon) $\mathrm{m}^{-2} \mathrm{~s}^{-1}$, the TBARs content decreased relative to the $7^{\text {th }}$ day of exposure (Fig. $5 A, B$ ), possibly indicating the adaptation of plants to the lighting regime. At $21 \mathrm{~d}$, the TBARs content decreased in both varieties compared with that on the $7^{\text {th }} \mathrm{d}$ of exposure (Fig. 5A,B).

$\mathrm{H}_{2} \mathrm{O}_{2}$ content: In the leaves of the control plants of both varieties, the $\mathrm{H}_{2} \mathrm{O}_{2}$ content was similar and averaged $0.5-0.8 \mu \mathrm{mol} \mathrm{g} \mathrm{g}^{-1}$ (FM) (Fig. 5C,D). With increasing light intensity and exposure duration, enhancement in the $\mathrm{H}_{2} \mathrm{O}_{2}$ content of both varieties was observed. However, the varieties significantly differed from each other in the dynamics of hydrogen peroxide content. The content of $\mathrm{H}_{2} \mathrm{O}_{2}$ in the leaves of green-leaved basil increased four times at $21 \mathrm{~d}$ of exposure at a light intensity of 1,350 $\mu \mathrm{mol}\left(\right.$ photon) $\mathrm{m}^{-2} \mathrm{~s}^{-1}$, and that in the purple-leaved basil increased on average three times, compared with that of the initial-point control (Fig. 5C,D).

\section{Discussion}

First, we investigated the relationship between the changes in the photosynthetic parameters during long-term HIL cultivation and changes in the carotenoid (Fig. 4A,B) and anthocyanin (Fig. $4 C, D$ ) content. We must understand how these pigments can support growth and PA activity under photoinhibition. Carotenoids and anthocyanin, which are found in different cell compartments, can perform common photoprotective functions, however, their mechanisms of action differ (Yin et al. 2015, Zhang et al. 2018, Kumar and Kim 2019).

Regarding the carotenoid content, the control plants, green-leaved basil and purple-leaved basil did not differ significantly (Fig. 4A,B). An increase in the carotenoid content in response to the HIL action is an important adaptive mechanism present in plants and algae (Vo et al. 2017, Wurtzel 2019). However, such a relationship is not always unambiguous. Thus, in the leaves of green-leaved basil, the carotenoid content increased markedly as the plants were exposed to light (Fig. 4A). By contrast, under the same conditions in purple-leaved basil, the carotenoid content decreased (Fig. 4B). In green-leaved basil plants, carotenoids appear to be an effective protective mechanism for PA protection, however, in purple-leaved basil plants,

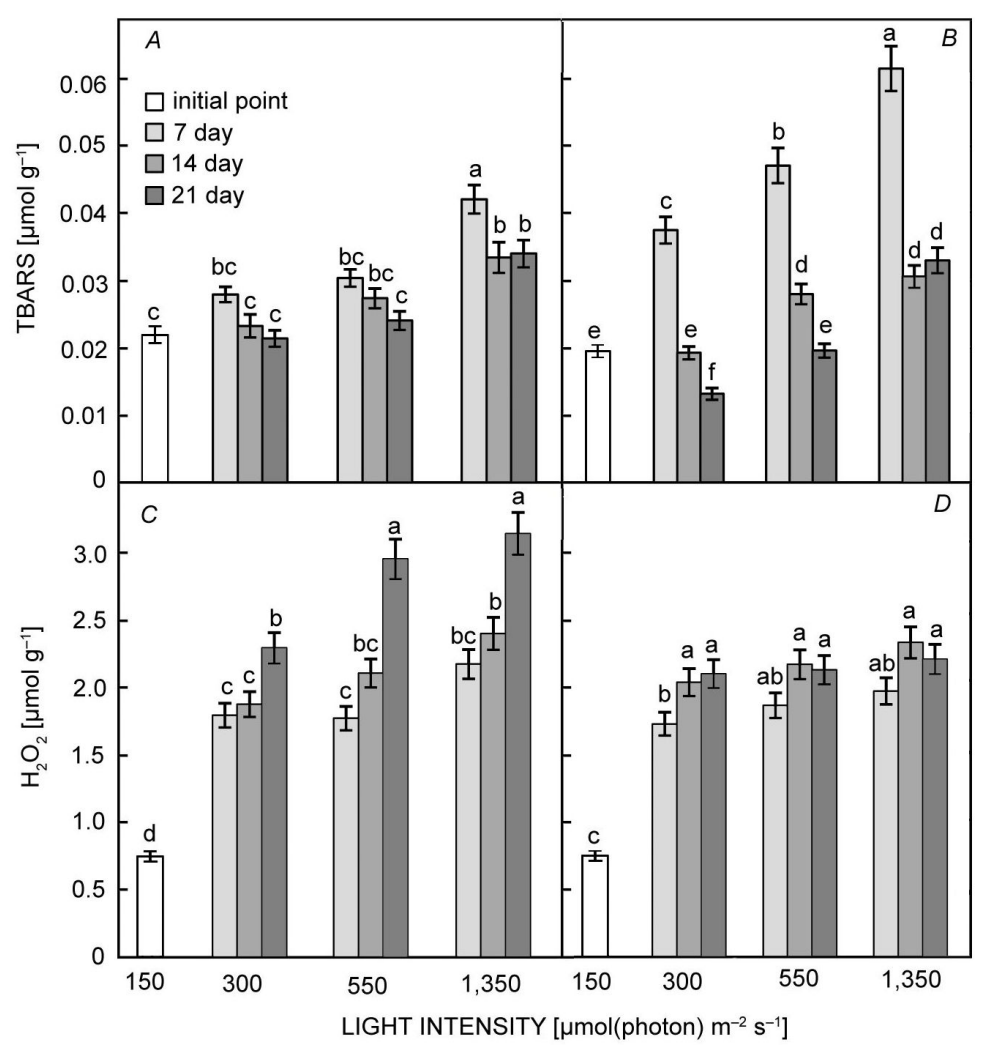

Fig. 5. Effect of different light intensities on the content of thiobarbituric acid reactive substances (TBARs) $(A, B)$ and $\mathrm{H}_{2} \mathrm{O}_{2}(C, D)$ in the leaves of green-leaved basil $(A, C)$ and purple-leaved basil $(B, D)$ plants grown under different exposure durations: 7, 14, and $21 \mathrm{~d}$. Light intensities: 150 (initial point), 300, 550, and 1,350 $\mu \mathrm{mol}$ (photon) $\mathrm{m}^{-2} \mathrm{~s}^{-1}$. Data were represented as mean $\pm \mathrm{SD}, n=6$. One-way analysis of variance (ANOVA) followed by Duncan's method were performed. Different letters were used to represent significance at $p<0.05$. 
this mechanism is less effective (Fig. $4 A, B$ ).

In sunlight, purple-leaved basil plants are more successfully adapted to brief and intense light of 2,000 $\mu \mathrm{mol}\left(\right.$ photon) $\mathrm{m}^{-2} \mathrm{~s}^{-1}$ due to the presence of UV in sunlight spectrum (Tattini et al. 2014). In the purple plant, epidermal coumaroyl anthocyanins play the role of an optical filter that prevents the penetration of UV into the mesophyll (Tattini et al. 2014). In purple-leaved basil plants, we observed a decrease in the pigments content and in the $\mathrm{Y}_{\text {(II) }}$ together with the increase in anthocyanin and TBARs (Figs. 2-4, Table 1). Landi et al (2014) showed that the isolated protoplasts of purple-leaved basil were more adapted to intense sun light, more likely due to the high content of ascorbate and glutathione than anthocyanin. We did not determine the content of these antioxidants, however, with respect to other studied parameters in purple-leaved basil at HIL, its protective resources were exhausted earlier and lost water in the end of the experiment was observed (Table 1).

With an increase in light intensity, green-leaved basil plants showed extended internodes, while purple-leaved, on the contrary, showed a decrease in the length of internodes and biomass (data not shown). The green-leaved PA is likely more plastic and, despite the increase in $\mathrm{H}_{2} \mathrm{O}_{2}$ content, continues grow successfully, maintaining a high content of pigments and an effective quantum yield (Fig. 2, Table 1).

It has been shown earlier that intense sunlight caused a stress phenotype in green basil (Tattini et al. 2014). These authors suggested that the absence of photomorphogenetic responses in purple-leaved plants growing under high UV irradiance was due to coumaroyl derivatives of cyanidin 3-O-glycosides distributed in adaxial and abaxial epidermis. The concentration of coumaroyl anthocyanin in purple-leaved basil is enhanced in sun leaves, thus constituting an effective shield (Edwards et al. 2008) against the penetration of UV wavelengths in the shade, not only in full sun (Tattini et al. 2014). It has been suggested that anthocyanin protect plants from UV more than from light of other wavelengths (Terashima et al. 2005).

It is known that an increase in the anthocyanin content is a widespread mechanism of plant adaptation to HIL (Shoji et al. 2010, Yin et al. 2015, Owen and Lopez 2017, Gould et al. 2018, Liu et al. 2018). In our experiments, the constitutive content of anthocyanin in purple basilic leaves was two times higher than that in green-leaved basil (Fig. 4C,D). Growth under intense light for $21 \mathrm{~d}$ led to slight enhancement in the anthocyanin content in green-leaved plants (Fig. 4C) and the almost six-fold increase in the anthocyanin content in purple-leaved basil compared with the initial-point control (Fig. 4D). In leaves concomitantly exposed to high temperature $\left(>33^{\circ} \mathrm{C}\right)$ and high sunlight irradiance $\left[>1,700 \mu \mathrm{mol}\left(\right.\right.$ photon) $\mathrm{m}^{-2} \mathrm{~s}^{-1}$ ] anthocyanin preserved photosynthesis in excess light (Tattini et al. 2014). In contrast to this, our experiments without high temperature effect showed that prolonged exposure to LEDs HIL reduces both the protective properties of anthocyanin and probably antioxidant abilities of purpleleaved basil mesophyll cells (Table 1). The effective PSII quantum yield $\mathrm{Y}_{(\mathrm{II})}$ in purple-leaved basil increased only at a moderate light intensity of $550 \mu \mathrm{mol}$ (photon) $\mathrm{m}^{-2} \mathrm{~s}^{-1}$, however, at a higher intensity, $\mathrm{Y}_{\text {(II) }}$ was noticeably lower than in green-leaved basil (Fig. 2).

In green- and purple-leaved basils, biomass was significantly different depending on light intensity (Table 1). It is known that flavonoid-rich ecotypes display reduced biomass production with respect to their flavonoid-poor relatives (Hofmann and Jahufer 2011). Anthocyanin-rich mutants of $A$. thaliana grow worse compared to a wild type (Misyura et al. 2013). The biosynthesis of phenylpropanoids is energetically expensive in purple-leaved plants, but the accumulation of these metabolites may be of benefit under a wide range of stress (Hatier et al. 2013, Tattini et al. 2014). The authors suggested that purple-leaved plants will likely perform poorly in environments at limited sunlight availability, as the suite of morphoanatomical and biochemical traits leads to low ability of light interception and transmission in the leaf (Tattini et al. 2014). However, our data indicate that purple-leaved basil in low light conditions $\left[\begin{array}{llll}150 & \mu \mathrm{mol}(\text { photon}) & \mathrm{m}^{-2} & \mathrm{~s}^{-1}\end{array}\right]$ only slightly exceeds growth parameters of green-leaved basil (Table 1). It is likely that the level of anthocyanin in low light is reduced, which allows increasing the penetration of light to the mesophyll (Fig. 4C,D).

The potential efficiency of PSII functioning is characterized by the maximum quantum yield $\left(\mathrm{F}_{\mathrm{v}} / \mathrm{F}_{\mathrm{m}}\right)$, however, under light conditions, this activity is characterized by the effective quantum photochemical yield of $\mathrm{Y}_{\text {(II) }}$ (Goltsev et al. 2016). This activity is also connected to the redox state of $\mathrm{Q}_{\mathrm{A}}$, which, assuming a lake model for PSII, is linearly related to the fluorescence parameter $\mathrm{q}_{\mathrm{L}}$ (Kramer et al. 2004). Even under HIL, green-leaved basil can maintain a high effective quantum photochemical yield of PSII for three weeks, although $\mathrm{F}_{\mathrm{v}} / \mathrm{F}_{\mathrm{m}}$ decreased slightly. Note, that the xanthophyll cycle is the main photoprotective mechanism functioning in photosynthetic organisms, which is associated with enzymatic reactions of epoxidation and deepoxidation of xanthophylls (Latowski et al. 2004). There is a close relationship between xanthophyll cycle and redox state of $\mathrm{Q}_{\mathrm{A}}$. So, investigations of Chlorella vulgaris culture demonstrated a correlation between increase in xanthophylls pool size and epoxidation of the pool pigments and redox state of $\mathrm{Q}_{\mathrm{A}}$, which was evaluated as $1-\mathrm{q}_{\mathrm{P}}$ (Wilson and Huner 2000). However, Kramer (2004) using the lake model, suggested to use new parameter $\mathrm{q}_{\mathrm{L}}$ (more suitable for terrestrial plants) instead of $\mathrm{q}_{\mathrm{P}}$ and submitted new evaluation of redox state of $\mathrm{Q}_{\mathrm{A}}$ as $1-\mathrm{q}_{\mathrm{L}}$.

In purple-leaved plants, we indicated a decrease in $\mathrm{q}_{\mathrm{L}}$ and hence increase in $1-\mathrm{q}_{\mathrm{L}}$ that in our opinion corresponds to more reduced $\mathrm{Q}_{\mathrm{A}}$ acceptor and lowered $\mathrm{Y}_{(\mathrm{II})}$. Therefore, in purple plants, we can suggest an increase in xanthophylls pool size as a protective mechanism against high irradiance. Decline in value of $Y_{(I)}$ in purpleleaved plants and high level of this yield in green-leaved plants are also in accordance with the data on changes in NPQ, which was maximal in purple-leaved plants on the $21^{\text {th }}$ day at light intensity of $1,350 \mu \mathrm{mol}$ (photon) $\mathrm{m}^{-2} \mathrm{~s}^{-1}$ but 
minimal in green-leaved plants.

Notably, no distinct correlation was found among the $\mathrm{F}_{\mathrm{v}} / \mathrm{F}_{\mathrm{m}}, \mathrm{q}_{\mathrm{L}}$, and $\mathrm{Y}_{\text {(II) }}$ values likely because of the increased content of pigment in the leaves. The purple-leaved basil, despite the loss of water and a decrease in growth parameters in $21 \mathrm{~d}$, retained the effective PSII quantum yield values close to that of the initial-point control [150 $\mu \mathrm{mol}$ (photon) $\mathrm{m}^{-2} \mathrm{~s}^{-1}$. However, $\mathrm{Y}_{\text {(II) }}$ was noticeably lower than that of green-leaved basil, consistent with several areas demonstrating low PSII photochemical activity in purple-leaved plants (Fig. $3 B$ ). Moreover, the anthocyanin content and amount of free phenolic compounds were increased against the background of a decrease in $\mathrm{H}_{2} \mathrm{O}_{2}$ and TBARs (Fig. 5), possibly indicating a high adaptive potential of the plants and the success of the strategy of the accumulation of anthocyanin under HIL conditions during long-term cultivation.

It was hypothesized that an inherently low ability to activate xanthophyll cycle pigments may be a feature of purple-leaved plants (Nikiforou and Manetas 2010, Tattini et al. 2014). In contrast to the green-leaved plants, we showed that the HIL significantly reduced the amount of carotenoids in the purple-leaved basil on the $21^{\text {st }}$ day of experiment even at $300 \mu \mathrm{mol}$ (photon) $\mathrm{m}^{-2} \mathrm{~s}^{-1}$ (Fig. 4A,B). The reduced pool of xanthophyll cycle pigments is related to photoinhibitory damage in basil, as also reported previously in a range of species (Hughes et al. 2012, Tattini et al. 2014). The authors hypothesized, that NPQ operated less in purple-leaved than in green-leaved plants, to dissipate excess photons reaching the photosynthetic apparatus, because fewer photons reached the chloroplast (Hughes et al. 2012, Tattini et al. 2014). However, when the light intensity was extremely high and influenced for a longer time, the NPQ of purple-leaved basil significantly increased, and the effective quantum yield of PSII was reduced (Fig. 2), in contrast to the short-term action of intense sunlight. The observed enhanced energy dissipation $\mathrm{Y}_{(\mathrm{NPQ})}$ in purple-leaved basil at HIL (compared with a control $\left[150 \mu \mathrm{mol}\left(\right.\right.$ photon) $\left.\mathrm{m}^{-2} \mathrm{~s}^{-1}\right]$ is a possible protection mechanism during long-time growing to reduce PA damage. It is possible that purple-leaved basil is able to cope with short, but intense light, which includes UV, due to NPQ, while in the long time HIL treatment NPQ does not allow to transform all excess energy into heat, which leads to photodamage and water loss (Fig. 2, Table 1).

In addition to anthocyanin, other phenolic compounds are present in plant cells that are also sensitive to light conditions and are involved in photoprotection and photorepair (Csepregi and Hideg 2018, Nadeem et al. 2019). There is evidence that phenylpropanoids can play an even more important role than anthocyanin and carotenoids in basil plants under HIL exposure. Thus, carbon investment to phenylpropanoid biosynthesis was much greater in purple- than that in green-leaved basil in the shade, and only partially due to anthocyanin biosynthesis (Tattini et al. 2014). Light-induced accumulation of phenylpropanoids was much greater in green-leaved than in purple-leaved plants in response to high sunlight (Tattini et al. 2014). However, we did not observe such carotenoid enhancement in green-leaved basil as anthocyanin in purple-leaved plants (Fig. 4). The contents of carotenoids were close to each other at 550 and $1,350 \mu \mathrm{mol}$ (photon) $\mathrm{m}^{-2} \mathrm{~s}^{-1}$ regardless of growing time.

In green basil, it is highly likely that PA is protected by other antioxidants. Nevertheless, the content of the total phenolic compounds was higher in purple basil, and only on $21 \mathrm{~d}$ both plants become equal in this parameter. Nazir et al. (2020) examined the antioxidant capacity of basil cell cultures under conditions of a different light spectrum. It turned out that the highest 2,2'-azino-bis (3-ethylbenzothiazoline-6-sulfonic acid (ABTS) activity of cell extracts was observed in the basilica cells exposed under the blue and white light. The free total phenolic and flavonoid contents were found to be positively correlated with antioxidant activities in cells (Ali and Abbasi 2014) and in whole plants of O. basilicum (Javanmardi et al. 2003, Carvalho et al. 2016, Nadeem et al. 2019). A similar correlation in our experiments was observed. HIL increased the total phenolic content in the leaves of both types of basil (Table 1), accompanied by a TBARs decrease at 14 and $21 \mathrm{~d}$ in both basil cultivars (Fig. 5A,B). The content of TBARs increased in both varieties in the first $7 \mathrm{~d}$ after the plants were kept at all light intensities which also were correlated with lowered content of phenolic compounds. This result suggests that both varieties adapt to HIL, however, the adaptation strategy of green basil is more successful, because it allows to maintain growth and $\mathrm{Y}_{\text {(II) }}$ for a long time at high irradiance. In this case, the purple-leaved basil is likely to adapt via the accumulation of phenolic compounds and anthocyanin, while the greenleaved basil is adapted via the accumulation of carotenoids, phenolic compounds, and anthocyanin (partially). However, significant accumulation of anthocyanin in purple leaves on $21 \mathrm{~d}$ leads to decrease in photosynthetic activity likely due to essentially lowered light intensity reaching light-harvesting complexes in chloroplasts as well as reduced contents of photosynthetic pigments.

Conclusion: Our results are consistent with the concept of the important role of both anthocyanin and carotenoids in plant adaptation to HIL. We suggest that HIL of 1,350 $\mu$ mol(photon) $\mathrm{m}^{-2} \mathrm{~s}^{-1}$ can be used for several weeks to enhance the nutritional and/or medicinal properties of basil. The optimal light intensity for growth is likely in the range of $550 \mu \mathrm{mol}$ (photon) $\mathrm{m}^{-2} \mathrm{~s}^{-1}$ because most of the studied parameters of the two plant species converged at this light intensity. A high carotenoid content serves as a more effective photoprotective mechanism for the long-term cultivation of the photophilous basil plants on HIL using white LEDs. Carotenoids are also more effective for the biomass accumulation of the aerial part of basil in a wider range of light intensities. By contrast, anthocyanin provides a high level of $\mathrm{Y}_{\text {(II) }}$ comparable to that of green-leaved basil at a moderate light intensity of $550 \mu \mathrm{mol}$ (photon) $\mathrm{m}^{-2} \mathrm{~s}^{-1}$ compared with that of greenleaved basil at the same light intensity. Our results with LED illumination, in aspects, contradict those obtained in sunlight. Probably, the adaptive potential of the purple basil is aimed specifically at short-term containment of the influence of UV, which is less effective with long-term 
exposure to narrow-band light. The anthocyanin protection of the purple-leaved basil is aimed at UV shielding, and the antioxidant system probably is also triggered by UV light.

\section{References}

Ali M., Abbasi B.H.: Light-induced fluctuations in biomass accumulation, secondary metabolites production and antioxidant activity in cell suspension cultures of Artemisia absinthium L. - J. Photoch. Photobio. B 140: 223-227, 2014.

Allakhverdiev S.I., Kreslavski V.D., Klimov V.V. et al.: Heat stress: An overview of molecular responses in photosynthesis. - Photosynth. Res. 98: 541, 2008.

Andersson B., Aro E.-M.: Photodamage and D1 protein turnover in photosystem II. - In: Aro E.-M., Andersson B. (ed.): Regulation of Photosynthesis. Advances in Photosynthesis and Respiration. Vol. 11. Pp. 377-393. Springer, Dordrecht 2001.

Aro E.-M., Virgin I., Andersson B.: Photoinhibition of photosystem II: inactivation, protein damage and turnover. - BBABioenergetics 1143: 113-134, 1993.

Bellincampi D., Dipperro N., Salvi G. et al.: Extracellular $\mathrm{H}_{2} \mathrm{O}_{2}$ induced by oligogalacturonides is not involved in the inhibition of the auxin-regulated rolB gene expression in tobacco leaf explants. - Plant Physiol. 122: 1379-1385, 2000.

Berry J.A., Björkman O.: Photosynthetic response and adaptation to temperature in higher plants. - Ann. Rev. Plant Physio. 31: 491-543, 1980.

Bidel L.P.R., Meyer S., Goulas Y. et al.: Responses of epidermal phenolic compounds to light acclimation: In vivo qualitative and quantitative assessment using chlorophyll fluorescence excitation spectra in leaves of three woody species. J. Photoch. Photobio. B 88: 163-179, 2007.

Carvalho S.D., Schwieterman M.L., Abrahan C.E. et al.: Light quality dependent changes in morphology, antioxidant capacity, and volatile production in sweet basil (Ocimum basilicum). - Front. Plant Sci. 7: 1328, 2016.

Cheynier V., Comte G., Davies K.M. et al: : Plant phenolics: recent advances on their biosynthesis, genetics, and ecophysiology. Plant Physiol. Bioch. 72: 1-20, 2013.

Csepregi K., Hideg E.: Phenolic compound diversity explored in the context of photo-oxidative stress protection. - Phytochem. Anal. 29: 129-136, 2018.

De Keyser E., Dhooghe E., Christiaens A. et al:: LED light quality intensifies leaf pigmentation in ornamental pot plants. - Sci. Hortic.-Amsterdam 253: 270-275, 2019.

Duarte J.H., de Souza C.O., Druzian J.I., Costa J.A.V.: Light emitting diodes applied in Synechococcus nidulans cultures: Effect on growth, pigment production and lipid profiles. Bioresource Technol. 280: 511-514, 2019.

Edwards W.R., Hall J.A., Rowlan A.R. et al.: Light filtering by epidermal flavonoids during the resistant response of cotton to Xanthomonas protects leaf tissue from light-dependent phytoalexin toxicity - Phytochemistry 69: 2320-2328, 2008.

Fan Y.G., Zhao X.X., Wang H.Y. et al.: Effects of light intensity on metabolism of light-harvesting pigment and photosynthetic system in Camellia sinensis L. cultivar 'Huangjinya'. Environ. Exp. Bot. 166: 103796, 2019.

Frank H.A., Cogdell R.J.: Carotenoids in photosynthesis. Photochem. Photobiol. 63: 257-264, 1996.

Giusti M.M., Wrolstad R.E.: Characterization and measurement with UV-visible spectroscopy. - In: Wrolstad R.E. (ed.): Anthocyanin. Current Protocols in Food Analytical Chemistry. Pp. 1-13. John Wiley \& Sons, New York 2001.

Goltsev V.N., Kalaji H.M., Paunov M. et al.: Variable chlorophyll fluorescence and its use for assessing physiological condition of plant photosynthetic apparatus. - Russ. J. Plant Physl+ 6: 869-893, 2016.

Gould K.S., Jay-Allemand C., Logan B.A. et al.: When are foliar anthocyanin useful to plants? Re-evaluation of the photoprotection hypothesis using Arabidopsis thaliana mutants that differ in anthocyanin accumulation. - Environ. Exp. Bot. 154: 11-22, 2018.

Gould K.S., Markham K.R., Smith R.H., Goris J.J.: Functional role of anthocyanin in the leaves of Quintinia serrata A. Cunn. - J. Exp. Bot. 51: 1107-1115, 2000.

Hatier J.H.B., Clearwater M.J., Gould K.S.: The functional significance of black-pigmented leaves: photosynthesis, photoprotection and productivity in Ophiopogon planiscapus 'Nigrescens'. - PLoS ONE 8: e67850, 2013.

Heath R.L., Packer L.: Photoperoxidation in isolated chloroplasts: I. Kinetics and stoichiometry of fatty acid peroxidation. Arch. Biochem. Biophys. 125: 189-198, 1968.

Hoagland D.R., Arnon D.I.: The water-culture method for growing plants without soil. - Soil Sci. 48: 1950.

Hofmann R.W., Jahufer M.Z.Z.: Tradeoff between biomass and flavonoid accumulation in white clover reflects contrasting plant strategies. - PLoS ONE 6: e18949, 2011.

Hosseini A., Mehrjerdi M.Z., Aliniaeifard S., Seif M.: Photosynthetic and growth responses of green and purple basil plants under different spectral compositions. - Physiol. Mol. Biol. Pla. 25: 741-752, 2019.

Huang W., Zhang S.B., Liu T.: Moderate photoinhibition of photosystem II significantly affects linear electron flow in the shade-demanding plant Panax notoginseng. - Front. Plant Sci. 9: 637, 2018.

Hughes N.M., Burkey K.O., Cavender-Bares J., Smith W.K.: Xanthophyll cycle pigment and antioxidant profiles of winterred (anthocyanic) and winter-green (acyanic) angiosperm evergreen species. - J. Exp. Bot. 63: 1895-1905, 2012.

Javanmardi J., Stushnoff C., Locke E., Vivanco J.M.: Antioxidant activity and total phenolic content of Iranian Ocimum accessions. - Food Chem. 4: 547-550, 2003.

Jensen N.B., Clausen M.R., Kjaer K.H.: Spectral quality of supplemental LED grow light permanently alters stomatal functioning and chilling tolerance in basil (Ocimum basilicum L.). - Sci. Hortic.-Amsterdam 227: 38-47, 2018.

Kalisz A., Pokluda R., Jezdinský A. et al.: Chilling-induced changes in the antioxidant status of basil plants. - Acta Physiol. Plant. 8: 196, 2016.

Khan T., Abbasi B.H., Khan M.A.: The interplay between light, plant growth regulators and elicitors on growth and secondary metabolism in cell cultures of Fagonia indica. - J. Photoch. Photobio. B 185: 153-160, 2018.

Klughammer C., Schreiber U.: Complementary PSII quantum yields calculated from simple fluorescence parameters measured by PAM fluorometry and the saturation pulse method. - PAM Appl. Notes 1: 27-35, 2008. http://www.walz. com/

Kramer D.M., Johnson G., Kiirats O., Edwards G.E.: New fluorescence parameters for the determination of $\mathrm{Q}_{\mathrm{A}}$ redox state and excitation energy fluxes. - Photosynth. Res. 79: 209, 2004.

Kumar P., Kim B.S.: Paracoccus sp. strain LL1 as a single cell factory for the conversion of waste cooking oil to polyhydroxyalkanoates and carotenoids. - Appl. Food Biotechnol. 6: 53-60, 2019.

Landi M., Guidi L., Pardossi A. et al.: Photoprotection by foliar anthocyanins mitigates effects of boron toxicity in sweet basil (Ocimum basilicum). - Planta 240: 941-953, 2014.

Latowski D., Grzyb J., Strzalka K.: The xanthophyll cycle - 
Molecular mechanism and physiological significance. - Acta Physiol. Plant. 26: 197-212, 2004.

Lefsrud M.G., Kopsell D.A., Sams C.E.: Irradiance from distinct wavelength light-emitting diodes affect secondary metabolites in kale. - HortScience 47: 2243-2244, 2008.

Lichtenthaler H.K.: Chlorophylls and carotenoids: pigment of photosynthetic biomembranes. - Method. Enzymol. 148: 350-382, 1987.

Liu Y., Tikunov Y., Schouten R.E. et al: : Anthocyanin biosynthesis and degradation mechanisms in Solanaceous vegetables: a review. - Front. Chem. 6: 52, 2018.

Lobiuc A., Vasilache V., Oroian M. et al.: Blue and red LED illumination improves growth and bioactive compounds contents in acyanic and cyanic Ocimum basilicum L. microgreens. - Molecules 22: 2111, 2017.

Manetas Y.: Why some leaves are anthocyanic and why most anthocyanic leaves are red? - Flora 201: 163-177, 2006.

Masondo N.A., Aremu A.O., Kulkarni M.G. et al.: How do different watering regimes affect the growth, chlorophyll fluorescence, phytohormone, and phenolic acid content of greenhouse-grown Ceratotheca triloba? - J. Plant Growth Regul. 38: 385-399, 2019.

Mierziak J., Kostyn K., Kulma A.: Flavonoids as important molecules of plant interactions with the environment. Molecules 10: 16240-16265, 2014.

Misyura M., Colasanti J., Rothstein S.J.: Physiological and genetic analysis of Arabidopsis thaliana anthocyanin biosynthesis mutants under chronic adverse environmental conditions. - J. Exp. Bot. 64: 229-240, 2013.

Mosadegh H., Trivellini A., Ferrante A. et al.: Applications of UV-B lighting to enhance phenolic accumulation of sweet basil. - Sci. Hortic.-Amsterdam 229: 107-116, 2018.

Nadeem M., Abbasi B.H., Younas M. et al.: LED-enhanced biosynthesis of biologically active ingredients in callus cultures of Ocimum basilicum. - J. Photoch. Photobio. B 190: 172-178, 2019.

Nazir M., Ullah M.A., Younas M.: Light-mediated biosynthesis of phenylpropanoid metabolites and antioxidant potential in callus cultures of purple basil (Ocimum basilicum L. var purpurascens). - Plant Cell Tiss. Org., 2020. https://doi. org/10.1007/s11240-020-01844-z (In press)

Nikiforou C., Manetas Y.: Strength of winter leaf redness as an indicator of stress vulnerable individuals in Pistacia lentiscus. - Flora 205: 424-427, 2010.

Ouzounis T., Rosenqvist E., Ottosen C.-O.: Spectral effects of artificial light on plant physiology and secondary metabolism: a review. - HortScience 50: 1128-1135, 2015.

Owen W.G., Lopez R.G.: Geranium and purple fountain grass leaf pigmentation is influenced by end-of-production supplemental lighting with red and blue light-emitting diodes. HortScience 52: 236-244, 2017.

Ramel F., Birtic S., Cuiné S. et al.: Chemical quenching of singlet oxygen by carotenoids in plants. - Plant Physiol. 158: 1267-1278, 2012.

Rodriguez-Amaya D.B.: Update on natural food pigment: A mini-review on carotenoids, anthocyanin, and betalains. Food Research Int. 124: 200-205, 2019.

Shoji K., Goto E., Hashida S. et al.: Effect of red light and blue light on the anthocyanin accumulation and expression of anthocyanin biosynthesis genes in red-leaf lettuce. - J. Sci. High Technol. Agric. 22: 107-113, 2010.

Singleton V.L., Orthofer R., Lamuela-Raventós R.M.: Analysis of total phenol and other oxidation substrates and antioxidants by means of Folin-Ciocalteu reagent. - Method. Enzymol. 299: 152-178, 1999.

Tattini M., Landi M., Brunetti C. et al.: Epidermal coumaroyl anthocyanins protect sweet basil against excess light stress: multiple consequences of light attenuation. - Physiol. Plantarum 152: 585-598, 2014.

Terashima I., Araya T., Miyazawa S.I. et al.: Construction and maintenance of the optimal photosynthetic systems of the leaf, herbaceous plant and tree: an eco-developmental treatise. - Ann. Bot.-London 95: 507-519, 2005.

Trojak M., Skowron E. Role of anthocyanin in high-light stress response. - World Sci. News 81:150-168, 2017.

Vo T., Tran S., Nguyen P., Mai T.: Growth, carotenoid production, antioxidant capacity and lipid accumulation of Haematococcus sp. under different light intensities. - Am. J. Plant Biol. 2: 142-147, 2017.

Wilson K.E., Huner N.P.A.: The role of growth rate, redox-state of the plastoquinone pool and the trans-thylakoid $\Delta \mathrm{pH}$ in photoacclimation of Chlorella vulgaris to growth irradiance and temperature. - Planta 212: 93-102, 2000.

Wurtzel E.T.: Changing form and function through carotenoids and synthetic biology. - Plant Physiol. 179: 830-843, 2019.

Yabuzaki J.: Carotenoids Database: structures, chemical fingerprints and distribution among organisms. - Database 2017: bax004, 2017.

Yin J.M., Yan R.X., Zhang P.T. et al.: Anthocyanin accumulation rate and the biosynthesis related gene expression in Dioscorea alata. - Biol. Plantarum 59: 325-330, 2015.

Zhang Y., Jiang L., Li Y. et al.: Effect of red and blue light on anthocyanin accumulation and differential gene expression in strawberry (Fragaria $\times$ ananassa). - Molecules 23: 820, 2018.

(C) The authors. This is an open access article distributed under the terms of the Creative Commons BY-NC-ND Licence. 